九州大学学術情報リポジトリ

Kyushu University Institutional Repository

\title{
Cost-benefit Analysis of the Log Gathering in Korea
}

Kim, Joon-Soon

Department of Forest Management, College of Forest and Environmental Sciences, Kangwon National University

Choi, Young-seop

Department of Forest Management, College of Forest and Environmental Sciences, Kangwon National University

Lee, Jung-soo

Department of Forest Management, College of Forest and Environmental Sciences, Kangwon National University

Cha, Du-song

Department of Forest Management, College of Forest and Environmental Sciences, Kangwon National University

他

https://doi.org/10.5109/22074

出版情報: 九州大学大学院農学研究院紀要. 57 (1)，pp.211-217，2012-02. Faculty of Agriculture， Kyushu University

バージョン :

権利関係 : 


\title{
Cost-benefit Analysis of the Log Gathering in Korea
}

\author{
Joon-soon KIM ${ }^{1}$, Young-seop CHOI ${ }^{1}$, Jung-soo LEE $^{1}$, Du-song CHA ${ }^{1 *}$ \\ and Shigejiro YOSHIDA
}

\author{
Laboratory of Forest Management, Division of Forest Sciences, Department of Agro-environmental Sciences, \\ Faculty of Agriculture, Kyushu University, Fukuoka 812-8581, Japan \\ (Received October 31, 2011 and accepted November 9, 2011)
}

\begin{abstract}
The gathering of political forest tending and forest biomass gathering have been enforced in Korea since 2009. However, the gathering has been enforced without checking feasibility of the policy, thereby causing a lot of controversy on the cost efficiency. Especially, the gathering quantity is calculated as $\mathrm{CO}_{2}$ emission of forest in IPCC guideline. Thus, cost-benefit analysis was carried out in this study to check the feasibility of the gathering policy enforced in Korea. For cost item, operating cost of political forest tending gathering and forest biomass gathering as well as $\mathrm{CO}_{2}$ loss quantity due to the gathering were selected and for benefit items, product sales income was selected to calculate the monetary value accordingly. However, labor cost of forest biomass log gathering was considered as transfer expenditure that is offset with effects of employment and it was excluded from evaluation. According to the result of cost-benefit analysis, the present value of cost is $2 \%$ higher than that of benefit. A sensitivity analysis showed that the most influential factor of internal return rate was found to be sales price of log. Further, it was found that the log should be sold over $356,000 \mathrm{~m}^{3}$ from 2012 to make the gathering policy feasible. To increase the sales quantity of the gathered logs, it is necessary to expand demanders by developing diverse uses such as wood chip and pellet and to organize professional gathering group to increase the gathering efficiency.
\end{abstract}

Key words: cost-benefit analysis, forest biomass, log gathering

\section{INTRODUCTION}

In Korea, forest tending is usually enforced by forestry cooperation and business related to forest as they are subcontracted by Korea Forest Service. Then, forest tending work is a concept including sapling tending, pruning, mowing, freeing from vines, thinning, natural forest tending and log gathering, but the portion of log gathering was very low before 2010. The portion of log gathering was low in forest tending, because the gathering cost was too expensive that the forest in Korea was mostly steep and infrastructure like forest road was insufficient. $^{2}$ Thus, it was difficult for business related to forest to make profit by log gathering. In order to promote utilizing log produced in the forest tending ${ }^{3}$, the government is subsidizing the cost of log gathering and pushing forward the operation of forest biomass gathering group in the cause of political forest tending and public forest tending to perform officially log gathering in the forest tending in designated rate from 2009. The log gathering of political forest tending is to add log gathering right after the general forest tending. Forest biomass gathering, is only performed log gathering without forest tending. In other words, if forest tending and log gathering are done together, it is the gathering of political forest tending. If only log gathering is done, it is forest biomass gathering. While the gathering of political forest tending aims to activate the utilization of forest, the main objective of forest biomass gathering is to create employment.

The ground of facilitating log gathering policy that

${ }^{1}$ Department of Forest Management, College of Forest and Environmental Sciences, Kangwon National University, Korea

* Corresponding author (E-mail: dscha@kangwon.ac.kr) was enforced in full scale since 2009 can be found in the data of input budget. Although 308,900 million won (Korean currency unit: won) was input to forest tending by Korea Forest Service in 2009, the rate of log gathering in the budget was only $0.6 \%$ (1,959 million won) (Korea Forest Service, 2010a). Entering 2010, however, the rate of log gathering in the budget was remarkably increased to $14.0 \%$ (44,820 million won). In the public forest tending, the budget rate of forest biomass log gathering was also increased from 27.6\% (47,183 million won) in 2009 to $34.6 \%$ (50,333 million won) in 2010. Further, getting out of the passive log gathering in the past which gathered only quite useful medium-diameter $\log$ (DBH $18 \mathrm{~cm}-30 \mathrm{~cm})$, small diameter log(DBH $10 \mathrm{~cm}-$ $15 \mathrm{~cm}$ ) is also gathered at present.

The log gathering is meaningful policy for creating employment and using bio-energy in relation to climate change. However, it is not desirable policy in the position

\footnotetext{
2 In 2009, the forest road density of Korea is $2.61 \mathrm{~m} / \mathrm{ha}$ (Korea Forest Service, 2010), which is far lower than that of Japan (5.4 m/ha), Norway $(10.1 \mathrm{~m} / \mathrm{ha})$, Canada $(10.6 \mathrm{~m} / \mathrm{ha})$, Sweden (11.6 m/ha), US (11.8 m/ha), UK (16.7 m/ha), Australia ( $18.0 \mathrm{~m} / \mathrm{ha})$, Switzerland (29.0 m/ha), Austria $(35.8 \mathrm{~m} / \mathrm{ha})$, Germany ( $44.9 \mathrm{~m} / \mathrm{ha})$, namely, the advanced forest countries. In the area with low forest road density, the work is far less efficient than area with high forest road density (Korea Forest Enterprise Corporate Association, 2010).

3 In Korea, public forest tending policy is done each year. Public forest tending is the policy done by government to employ non-regular employees so as to create employment. As such, it is divided into public forest tending, forest biomass gathering group and forest tending resources survey group. Among them, forest biomass gathering group can acquire certain income by selling gathered product in addition to creating employment.
} 
to reflect carbon loss quantity for gathering fuel, according to IPCC guideline. The log gathering policy currently in force is not realized on the premise of concrete feasibility test reflecting carbon loss cost due to gathering fuel log and benefit caused by utilization of bio-energy. Although studies presenting the politic suggestion related to forestry is carried out in diverse methods in the country, specific study related to log gathering was not researched.

The typical way to assess public policy like log gathering is cost-benefit analysis. In cost-benefit analysis, all situations caused by policy are assessed including explicit cost and benefit as well as potential cost and benefit. In general, the effect of many policies done for forest are not available from market information. In this case, the value of target to be assessed through hypothetical condition can be acquired. The case of assessing forest value is applied in diverse areas. The studies related to conservation value of forest are Lockwood et al. (1993), Kniivilä et al. (2002), Wilson et al. (2010). Further, the studies of cost-benefit analysis that was restricted to assessment of conservation value of forest were expanded to diverse fields as their scope was broadened (Rueff et al., 2008; Sharma, 1997; Shaw, 2001; Zida and Force, 1990).

Albers and Robinson (2007) assessed the activities related to forest which were permitted in Khao Yai National Park, Thailand by using cost-benefit analysis. Slaney et al. (2010) performed the cost-benefit analysis of control program that prevented damage caused by blights and harmful insects in the forest. Then, Chen et al. (2010) analyzed the influence of spontaneous timber certification on the private cost and benefit to assess diverse materials related to forest, namely, the utilization of cost-benefit analysis.

The procedure of cost-benefit analysis is generally composed of 6 stages, that is, 1) discernment and classification of alternatives, 2) decision of policy life, 3) decision of discount rate, 4) selection of method to measure effect, 5) estimating cost and benefit, 6) sensitivity analysis. To check feasibility of log gathering policy by applying this procedure so as to assess degree of influence on change in profitability by sensitivity analysis of each factor, this study presented minimum sales quantity of log gathered through cost-benefit analysis in consideration of carbon loss quantity. Finally, the way gathering policy was suggested.

\section{ANALYTIC PROCEDURE AND METHODS}

\section{Selection of analysis scope and analysis items}

This study limited its scope to log gathering of political forest tending and log gathering of forest biomass initiated by government so as to calculate monetary value of cost items and benefit items caused by enforcing project. As invisible effect that can be acquired by log gathering, the development of lower plant, reduction of damage in the rainfall, reduction of possibility of forest fire, etc could be considered. However, they were excluded from object of analysis, because converting them into quantitative value is subject to limit. As cost items utilized in analysis, operating cost of log gathering policy and $\mathrm{CO}_{2}$ loss cost due to log gathering are considered, because log gathering in forest land should be calculated as $\mathrm{CO}_{2}$ loss according to IPCC guideline. However, labor cost for log gathering of forest biomass in the operating cost was excluded from analysis, because it was considered as transfer expenditure to employment effect. The sales income of log was used as benefit items. Finally, cost items by log gathering policy was considered as operating cost excluding labor cost and $\mathrm{CO}_{2}$ loss quantity by log gathering and benefit items, as sales income of product (Table 1).

Table 1. Cost and benefit items of the log gathering policy

\begin{tabular}{ll}
\hline & Items \\
\hline Cost & $\begin{array}{l}\text { - Operating cost of log gathering policy (excluding } \\
\text { labor cost for log gathering of forest biomass) }\end{array}$ \\
\hline Benefit & $\bullet \mathrm{CO}_{2}$ loss quantity caused by log gathering \\
\hline
\end{tabular}

\section{Decision of policy life and discount rate}

As log gathering policy is enforced as per regular goal quantity and goal amount each year, 1 year is applied as policy life. The discount rate applicable to cost-benefit analysis is market interest rate, marginal production of investment, government discount rate, business discount rate, personal discount rate, social discount rate, etc (Kim, 2000). While social discount rate is usually used in the cost-benefit analysis, there are various opinions on the level of discount rate to be fixed. ${ }^{4}$

The social discount rate is divided into social time preference rate, consumption interest rate, production interest rate, marginal return rate of private capital, opportunity cost of public investment, social investment return rate, etc depending on theoretic basis and deducting method (Lind, 1982). Jang (2010) estimated proper social discount rate by weighted average of social time preference rate and investment return rate of private capital. This study applied 3.15\%, mean value of the social discount rate in the data from 2004 to 2008 among diverse social discount rates deducted by Jang (2010).

\section{Establishing opportunity cost of cost and benefit items}

This study converted cost and benefit presented in the data of log gathering enforced in the country in 2009 on the basis of 2010. To calculate operating cost of log gathering policy, it is required to consider both log gathering of political forest tending and log gathering of forest biomass. The analysis utilized data on the operating cost of log gathering enforced by Korea Forest Service in 2009. $\mathrm{CO}_{2}$ loss quantity caused by log gathering was calculated on the basis of IPCC guideline (2006) and it was

\footnotetext{
${ }^{4}$ For argument on social discount rate, refer to Marglin (1963), Feldstein (1964) and Baumol (1969).
} 
converted to monetary value by multiplying the calculated $\mathrm{CO}_{2}$ quantity with trade price of CER. The value of sold product was calculated by multiplying sales quantity for each use with sales price of product for each use announced by government.

\section{Selecting the criterion of decision making and establishing sensitivity analysis items}

Based on the result of cost-benefit analysis, the feasibility of policy was assessed by calculating benefit-cost ratio and internal return rate as the criterion to decide whether policy is feasible or not. Since enforcement policy may be affected by unexpected external situation in actual operation of public project or policy, sensitivity analysis is required to rational decision through prior analysis. Sensitivity analysis helps final decision makers of project or policy to select and provides information so that they can take prior preventive action for successful enforcement. Depending on methodology, sensitivity analysis is divided into subjective forecast, selective sensitivity analysis and general sensitivity analysis (Kim, 2004). Subjective forecast can be deemed as the fastest and simplest method in that it is to forecast the possible change in the future based on subjective judgment. Selective sensitivity analysis is to consider selected specific situations in the diverse changing situations through objective check-up. Finally, general sensitivity analysis is a method to generally arrange and analyze future situation by listing all possible changing situations. Among the items that directly affect cost and benefit of log gathering, this study performed sensitivity analysis considering all exogenous variables, namely, operating cost of policy, sales price of product, trade price in the carbon market.

\section{RESULTS}

\section{Result of cost-benefit analysis}

Since log gathering is done by the log gathering of political forest tending and the log gathering of forest biomass, the sum of operating cost for these 2 policies can be deemed as actual cost. Operating cost for log gathering of political forest tending is divided into labor cost, equipment purchase cost and equipment maintenance cost. While labor cost occupies about $2 / 3$ of total cost, equipment purchase cost and equipment maintenance cost occupies about 1/3. Meanwhile, the operating cost for log gathering of forest biomass is mostly paid for labor cost. ${ }^{5}$

In 2009, equipment purchase cost was paid for log gathering of political forest tending and log gathering of forest biomass in the amount of 1,188 million won and 1,238 million won respectively. Since life expectancy is applied to the equipment necessary for log gathering, however, the equipment purchase cost for log gathering is divided by respective life expectancy ${ }^{6}$, so that it can be converted into present value. The present value of operating cost for log gathering converted by generalizing above result was 7,248 million won.

Due to log gathering, forest loses $\mathrm{CO}_{2}$ in the quantity equivalent to that of used product. IPCC (2006) data was used to quantify it by applying the formula (1).

$$
\mathrm{L}_{\text {residual } \log }=\mathrm{G} \times \mathrm{D} \times \mathrm{CF}
$$

$\mathrm{L}_{\text {residual log }}$ (Annaul carbon loss in biomass of residual log collection) $=$ annual carbon loss quantity of biomass due to log gathering (tC/yr)

$\mathrm{G}$ (Amount of Gathering) = volume of gathered product $\left(\mathrm{m}^{3} / \mathrm{yr}\right)$

$\mathrm{D}\left(\right.$ Basic wood density) $=$ basic wood density $\left(\mathrm{t} / \mathrm{m}^{3}\right)$

$\mathrm{CF}$ (Carbon Fraction) $=$ carbon rate of dry materials $(\mathrm{tC} / \mathrm{t})$

IPCC (2006) provides formula of carbon emission in diverse conditions and fields as well as coefficients applicable worldwide. However, coefficient to be applied in specific area or certain conditions is quite different from study data which was directly experimented on the site. Thus, the formula in this study used the data of IPCC

Table 2. The present value of operating cost for the log gathering(Unit : million won)

\begin{tabular}{lccr}
\hline & Political forest tending & Log gathering group & Total \\
\hline Labor cost & 619 & $(41,300)$ & 619 \\
Incidental cost & & 5,018 & 5,018 \\
Equipment purchase cost* & 135 & 149 & 284 \\
Equipment maintenance cost* & 214 & & 214 \\
Training expense & & 1,114 & 1,114 \\
Total & 968 & 6,280 & 7,248
\end{tabular}

* Equipment purchase cost and equipment maintenance cost means total cost to purchase, maintain and control all equipments necessary for log gathering.

\footnotetext{
As labor cost of product gathering is transfer expenditure, it is excluded from cost-benefit analysis.

${ }^{6}$ For product gathering of political forest tending, tower-yarder with tractor, wood grab, lease vehicle, small cable winch, small winch, trailor, tower yarder, excavator, cargo truck, sawdust producer, etc are used and small winch, electric saw, reaper, etc are included in equipment purchase cost for product gathering of forest biomass. The average service life of equipment necessary for product gathering of political forest tending is 8.8 years and that of equipment used for product gathering of forest biomass is 8.3 years (Korea Forest Service, 2010a; Public Procurement Service, 2009)
} 
(2006), but utilized domestic study data as coefficient for each factor.

The total volume of log gathered in the whole forest was counted to $819,296 \mathrm{~m}^{3}$ in 2009 (Korea Forest Service, 2010). D is conversion coefficient that converts cubic meter $\left(\mathrm{m}^{3}\right)$ into ton (t) unit as basic wood density. Korea Forest Research Institute (2006) deducted the basic wood density (D) of 11 main trees in Korea to meet division of tree age (below 20 years, 21-40 years, over 41 years). The average basic wood density of 11 trees, 0.461, was applied in this study.

For carbon rate of dry materials expressed in carbon conversion coefficient (CF), 0.47 pertaining to temperate climate zone was applied (IPCC, 2006). Through the above result, 274,977tC was finally calculated and was multiplied by $44 / 12$ to be converted into $\mathrm{CO}_{2}$ unit. To convert the $\mathrm{CO}_{2}$ value into monetary value, trade price of forest carbon market, $\$ 7.17 / \mathrm{tCO}_{2}{ }^{7}$ was applied and the present value of annual loss quantity calculated by applying it was 6,128 million won. Among the quantity of product gathered in $2009,819,296 \mathrm{~m}^{3}$, the quantity of product that could be reused to produce sawdust, pulp wood, sawn wood, 278,644 $\mathrm{m}^{3}$ was sold and residual quantity, 540,652 $\mathrm{m}^{3}$ which could not be as such was gratuitously provided free of charge to livestock farm and farming house. Thus, the income earned by selling the gathered product was applied only to $278,644 \mathrm{~m}^{3}$ and basic wood density, 0.461 was used to convert cubic meter $\left(\mathrm{m}^{3}\right)$ into tonne $(\mathrm{t})$. The log converted into $\mathrm{t}$ is sold to companies by usage at respectively different price. Log for sawdust is mostly sold to sawdust manufacturer at the price of $61,000 \mathrm{won} / \mathrm{t}$ to $77,000 \mathrm{won} / \mathrm{t} .{ }^{8}$ Thus, the mean value of market price scope, 69,000 won/t was applied. The price of lumber sold to sawmill was in the range of $81,000 \mathrm{won} / \mathrm{t}-103,000 \mathrm{won} / \mathrm{t}$ depending on the type and grade of tree. Then, announced sales data was calculated in average to apply general price. ${ }^{9}$ The lumber to produce pulp and MDF also varies depending on type and grade of tree. Thus, the average market price of forest product in 2010 by Northern Regional Forest Service (2010), 67,300 won/t was applied. The present value of selling product such as sawdust, lumber and other use is 13,120 million won.

As specified in Table 5, the benefit-cost ratio was cal-

Table 3. The basic wood density of 11 main trees in Korea

\begin{tabular}{cccccc}
\hline & $\begin{array}{c}\text { Pinus densiflora } \\
\text { in northern area }\end{array}$ & $\begin{array}{c}\text { Pinus densiflora } \\
\text { in central area }\end{array}$ & $\begin{array}{c}\text { Pinus } \\
\text { koraiensis }\end{array}$ & $\begin{array}{c}\text { Larix } \\
\text { kaempferi }\end{array}$ & $\begin{array}{c}\text { Pinus } \\
\text { rigida }\end{array}$ \\
\hline $\mathrm{D}$ & 0.368 & 0.388 & 0.324 & 0.481 & 0.465 \\
\hline & $\begin{array}{c}\text { Quercus } \\
\text { variabilis }\end{array}$ & $\begin{array}{c}\text { Quercus } \\
\text { mongolica }\end{array}$ & $\begin{array}{c}\text { Quercus } \\
\text { acutissima }\end{array}$ & $\begin{array}{c}\text { Pinus } \\
\text { thunbergii }\end{array}$ & $\begin{array}{c}\text { Cryptomeria } \\
\text { japonica }\end{array}$ \\
\hline $\mathrm{D}$ & 0.600 & 0.589 & 0.616 & 0.434 & 0.361 \\
\hline
\end{tabular}

Source: Korea Forest Research Institute (2006)

Table 4. The present value of selling product

\begin{tabular}{lrrrc}
\hline & Sawdust & Lumber & Others* & Total \\
\hline Sales quantity(t) & 24 & 92 & 13 & 128 \\
Sales price(won/t) & 72 & 111 & 63 & - \\
Sales income(million won) & 1,729 & 10,186 & 804 & 12,719 \\
Present value of income earned by selling (million won) & 1,784 & 10,507 & 829 & 13,120
\end{tabular}

* The materials to produce pulp and MDF.

Table 5. The present value of cost and benefit for each items

\begin{tabular}{llc}
\hline Items & & Present value (million won) \\
\hline \multirow{3}{*}{ Cost } & Operating cost of log gathering policy & 7,248 \\
& $\mathrm{CO}_{2}$ loss quantity caused by log gathering & 6,128 \\
& Sub-total & 13,376 \\
\hline \multirow{3}{*}{ Benefit } & Income from selling product & 13,120 \\
& Sub-total & 13,120 \\
\hline
\end{tabular}

\footnotetext{
${ }^{7}$ The trade price of forest carbon market presented by Ecosystem Marketplace was applied in weighted value (Hamilton et al., 2010).

${ }^{8}$ Hongcheon Forestry Cooperative (2009)

${ }^{9}$ Northern Regional Forest Service (2010)
} 
Table 6. Result of sensitivity analysis

\begin{tabular}{lccc}
\hline & Sensitivity index* & Width of change (\%) & IRR (\%) \\
\hline Basic value & - & - & 1.17 \\
Operating cost & 0.39 & -9 & 4.65 \\
Sale price of product & 2.64 & +2 & 6.45 \\
Carbon price & 0.82 & +4 & -2.09 \\
\hline
\end{tabular}

* Sensitivity index $=$ Change rate of IRR (\%) / Change rate of related variables (\%)

Table 7. The minimum sales quantity and rates

\begin{tabular}{lcccc}
\hline & 2009 & 2010 & 2011 & After 2012 \\
\hline Quantity of log gathering $\left(\mathrm{m}^{3}\right)$ & 819,296 & $1,030,000$ & $1,150,000$ & $1,270,000$ \\
Minimum sale quantity $\left(\mathrm{m}^{3}\right)$ & 284,088 & 317,560 & 336,623 & 355,686 \\
Rate of minimum sale quantity (\%) & 34.67 & 30.83 & 29.27 & 28.01 \\
\hline
\end{tabular}

culated to 0.98 . Although the objective of log gathering policy is to promote the utilization of product and employment, the rate of benefit and cost below 1 is negative in enforcing policy. Further, the IRR which means the discount rate where present value of benefit and that of cost for all term when project or policy is enforced is $1.17 \%$. As discount rate applied by IRR is lower than 3.15\% in this study, it is not persuasive to enforce policy same to the result of benefit-cost ratio.

To compare how much the change in each exogenous variable affects net benefit in sensitivity analysis, sensitivity index was calculated to standardize unit. As a result, the sensitivity index of sales price of product sales was 2.64, which was highest among the considered exogenous variables. This implies that IRR is most seriously affected by change in sale price. Meanwhile, the sensitivity index of operating cost and carbon price was found to be 0.39 and 0.82 respectively.

Considering the change in the real market related to forestry, operating cost tends to decrease as use rate and experts of forestry machine is gradually increasing. This is supported by the result of study made by Ministry of Knowledge Economy (2007), Lee and Ryu (2008), Kim (2010), etc. At present, log gathering of political forest tending and log gathering of forest biomass are mostly done by manual ground skidding. According to guideline of forest tending design, supervision and project implementation of forest tending used by domestic forest corporate body which mainly manages log gathering of political forest tending (2010), 1,997,000 won was spent to gather product in $40 \mathrm{~m}^{3} /$ ha in the forest where gathering distance was below $50 \mathrm{~m}$ and slope was medium. According to Kim (2010), 1,832,000 won is spent to gather product in $40 \mathrm{~m}^{3} /$ ha by using toweryarder with tractor. Namely, using tower-yarder with tractor in the forest in the same conditions, the cost is lower than that of manual ground skidding by some $9 \%$, which was set as changing rate of operating cost. Compared to the price of domestic lumber in 8 years ago, it rose by some $17 \%$, which is equivalent to $2.1 \%$ in annual average. Considering this point, $+2 \%$ was applied as variation rate. Adams (2006) forecast the carbon price in 2015 and 2025 on the basis of tendency of carbon price in Europe until 2005. The result was annual price increasing rate in $4.3 \%$. Referring to the data of Adams (2006), $+4 \%$ was applied in this study as variation rate of carbon price. It was forecasted that operating cost would be the most influential factor among those which can affect actual IRR among the considered exogenous variables.

\section{Estimating the minimum sales quantity of log gath- ering}

The quantity in log gathering is largely divided into 2 items. They are is the quantity of log gathering and sold. However, national policy data was utilized for the quantity of log gathering and only minimum sale quantity was estimated in comparison with total quantity of log gathering, because the Korea Forest Service presented the planned quantity of annual log gathering up to 2017 on the basis of the 5th National Forest Plan. The minimum sale quantity means the product quantity when total cost and total benefit of log gathering are same. As the Korea Forest Service (2007) equally applied 1,270,000 m³/year as the planned quantity of log gathering for the term from 2012 to 2017, the minimum sale quantity after 2012 was excluded from the forecast target. Some $819,000 \mathrm{~m}^{3}$, $27 \%$ of total product quantity of forest tending is currently gathered in the country and some $279,000 \mathrm{~m}^{3}$ (34\%) was sold among gathered product. Although total quantity of product gathered in forest tending is increasing in certain level each year, policy is not feasible, unless it is sold. Thus, product more than certain quantity of gathered product should be sold. Calculating the minimum sale quantity for 2009 , some $284,000 \mathrm{~m}^{3}$ should be sold on the basis of quantity of gathered product, $819,000 \mathrm{~m}^{3}$. The minimum sale quantity based on quantity of log gathering for 2010, 2011 and 2012 planned by the Korea Forest Service was found to be $318,000 \mathrm{~m}^{3}$, $337,000 \mathrm{~m}^{3}$ and $356,000 \mathrm{~m}^{3}$ respectively. However, it was found that the minimum sales rate gradually decreased as quantity of log gathering was increased. 


\section{SUMMARY AND CONCLUSION}

This study performed cost-benefit analysis by log gathering to assess the feasibility of log gathering policy. Cost items are operating cost of log gathering policy and $\mathrm{CO}_{2}$ loss quantity caused by log gathering and benefit item is sale income of product, and then cost and benefit items is quantified. Since labor cost for log gathering of forest biomass in cost items is deemed as transfer expenditure that is offset with employment creation effect pertaining to benefit, it is excluded from object of assessment. As a result, the present value of cost is found to be higher than present value of benefit by some $2 \%$. According to methodology of cost-benefit analysis, the currently enforced log gathering policy is not feasible in terms of policy. Further, analyzing sensitivity by selecting the operating cost of log gathering, sale price of product and carbon price as items, the sale price of product was found to be the most influential factor of policy. Finally supposing that there is no change in the operating cost, sale price of product and carbon price, it was found that net benefit could be realized if selling more than $356,000 \mathrm{~m}^{3}$ after 2012 . The product gathered after forest tending is mostly medium-diameter log and smalldiameter log. Thus, it is difficult to sell them at the price comparable to that of large-diameter log that occurs after deforestation. Therefore, increasing sale quantity above present level is possible only when corroborative review is made later, because the quantity is deficient. In addition to the method to increase sales quantity to certain level, however, the methods to find new demander can be studied by developing diverse uses, for example, supplying certain rate of gathered product to wood pellet factory which is considerably supported by state at present. The log gathering of political forest tending is currently being mechanized and log gathering of forest biomass is done by manual ground skidding. Thus, subsidiary policy seems necessary to improve efficiency of log gathering, for example, inducing competition in gathering group by paying allowance differently to employees of log gathering of forest biomass, depending on their result.

Although domestic data should be used for analysis pertaining to domestic situation, foreign data was partially used, because there is no study at all on log gathering policy so far. As the object of this study was limited to the log gathering policy, the cost and benefit of forest tending performed before/after log gathering, forest disaster (mountain fire, land slide, etc), etc was not included in the items. These items may be performed later. Since log gathering policy is quite closely related to forest tending policy and wood pellet supply policy, more persuasive result may be acquired if scope of analysis is extended up to the pervasive effect in the industrialization process so as to grasp the feasibility of domestic forestry policy.

\section{ACKNOWLEDGEMENTS}

This study was carried out with the support of
'Forest Science \& Technology Projects (Project No. S110910L060120)' provided by Korea Forest

\section{REFERENCES}

Adams, R. 2006 World carbon black demand forecast to go on notching up 4\% annual growth. Focus on Pigments, $\mathbf{2 0 0 6}(6)$ : $1-2$

Albers, H. J. and E. J. Robinson 2007 Spatial-temporal aspects of cost-benefit analysis for park management An example from Khao Yai National Park, Thailand. Journal of Forest Economics, 13(1-2): 129-150

Barreto, P., P. Amaral, E. Vidal and C. Uhl 1998 Costs and benefits of forest management for timber production in eastern Amazonia. Forest Ecology and Management, 108(1-2): 9-26

Baumol, W. 1969 On the appropriate discount rate for evaluation of public projects. In "Program budgeting and benefit-cost analysis", ed. by H.H. Hinrichs and G. M. Taylor, Goodyear Pub. Co., Los Angeles, pp. 202-212

Chen, J., J. L. Innes and A. Tikina 2010 Private cost-benefits of voluntary forest product certification. International forestry review, 12(1): 1-12

Hamilton, K., U. Chokkalingam and M. Bendana 2010 State of the Forest Carbon Markets 2009: Taking Root and Branching out. Ecosystem Marketplace, Washington, D. C. p. 70

Feldstein, M. S 1964 The social time preference discount rate in cost-benefit analysis. The Economics Journal, 74(294): 360-379

Hongcheon Forestry Cooperative 2009. Information of Hongcheon Sawdust Factory. p. 1

IPCC2006 2006 IPCC Prepared by the National Greenhouse Gas Inventories Programme. IGES, Japan

Jang, B. C. 2010 Study on Estimation of Social Discount Rate for Evaluating Public Investment Project. University of Seoul, p. 45

Kim, D. K. 2004 Cost-Benefit Analysis. Pakyoungsa,Seoul, p. 314

Kim, H. B 2000 Cost-Benefit Analytics. Hongmoonsa,Seoul, p. 396

Kim, J. H 2010 An analysis of the yarding productivity and cost in forest management operation. Kyungpook National University, p. 39

Kim, T. Y and S. B. Kim 2004 A Theory and Practice of CostBenefit Analysis; Public Project Evaluation and Regulatory Impact Analysis. Pakyoungsa,Seoul, p. 436

Kniivilä, M., V. Ovaskainen and O. Saastamoinen 2002 Costs and benefits next term of forest conservation: regional and local comparisons in Eastern Finland. Journal of Forest Economics, 8(2): $131-150$

Korea Forest Enterprise Corporate Association 2010 Forest Engineering Information. http://www.koreaforest.org/sub_4_4. htm (2010. 8. 16)

Korea Forest Research Institute 2006 Establishment on Statistics System for Greenhouse Gas Emission with UNFCCC in Forest Sector. Korea Forest Research Institute, p. 221

Korea Forest Service 2007 Effect of Forest Disaster on the Leaving of Thinning Slash. Korea Forest Service, p. 133

Korea Forest Service 2009 A Business Plan of Forestry Machine Field. Korea Forest Service, p. 23

Korea Forest Service 2010a Forest Tending Design, Supervision and Project Implementation Guideline. Korea Forest Service, p. 115

Korea Forest Service 2010b Statistical Yearbook of Forestry in 2010. Korea Forest Service, p. 491

Korea Forest Service 2010c The 5th National Forest Plan. Korea Forest Service, p. 198

Lee, K. H and J. H. Ryu 2008 Forest Tending Biomass Gathering Method. Forest Technology, 6: 275-277

Lind, R. C. 1982 A primer on the major issues relating to the discount rate for evaluating national energy options. In "Discounting for Time and Risk in Energy Policy", ed. by Robert C. Lind et al., Resources for the Future,Washington, 
D.C. pp. 21-94.

Lockwood, M., J. Loomis and T. DeLacy 1993 A Contingent Valuation Survey and Benefit-Cost Analysis of Forest Preservation in East Gippsland, Australia. Joumal of Environmental Management, 38(3): 233-243

Marglin, S. A. 1963 The social rate of discount and the optimal rate of investment. Quarterly Journal of Economics 77(1): $95-111$

Ministry of Knowledge Economy 2007 A Study on the Energy Utilization of Ligneous Biomass: Focusing on Energy Production Facility by Wood-chips. Ministry of Knowledge Economy, p. 482

Northern Regional Forest Service 2010 A Market Price of Forest Product in 2010. Northern Regional Forest Service, p. 3

Public Procurement Service 2009 Service Life. http://www.pps. go.kr/user.tdf? $a=$

Rueff, H., G. Kressel and M. Schwartz 2008 Forest Fire Control and Bedouin Pastoralism in Israel's Afforested Drylands: A Cost Benefit Analysis. Nomadic Peoples, 36: 923-930

Sharma, R. A. 1997 A Framework for the Cost-Benefit Analyses of Social Forestry. Indian Forester, 123(11): 986-995

Shaw, G. 2001 A cost-benefit analysis of long-term management options for forests following contamination with $137 \mathrm{Cs}$. Journal of Environmental Radioactivity, 56(1-2): 185-208

Slaney, G. L., V. A. Lantz and D. A. MacLean 2010 Assessing costs and benefitsnext term of pest management on forested landbases in eastern and western Canada. Journal of Forest Economics, 16(1): 19-34

Wilson, J. J., A. L. Van, D. A. MacLean 2010 A benefit-cost analysis of establishing protected natural areas in New Brunswick, Canada. Forest Policy and Economics, 12(2): 94-103

Zida, B. O. and J. E. Force 1990 Cost benefit analysis for fuelwood project investment in Burkina Faso: the case of Ouagadougou. Saf Publications, 2: 602-603 